\title{
Spectrophotometric Determination of Fluoride in Groundwater Using Resorcin Blue Complexes
}

\author{
Zaher Barghouthi ${ }^{1}$, Sameer Amereih ${ }^{2 *}$ \\ ${ }^{1}$ National Agricultural Research Center (NARC), Jenin, Palestine \\ ${ }^{2}$ Palestine Technical University-Kadoori, Tullkarm, Palestine \\ Email: "s.bsharat@ptuk.edu.ps
}

Received June 30, 2012; revised July 28, 2012; accepted August 15, 2012

\begin{abstract}
New simple and sensitive spectrophotometric determination of fluoride in drinking groundwater has been developed using aluminium-resorcin blue complex. The method is based on the reaction of fluoride with the coloured complex to produce colourless aluminium fluoride complex and releasing of the free ligand. The relationship of the reaction of fluoride with the complex is sixth-order polynomial function. The reaction reaches equilibrium at fluoride concentration of $0.054 \mathrm{mM}$. The equilibrium constant $\left(K_{e q}\right)$ was calculated as $1.12 \times 10^{14}$. Beer-Lambert law is obeyed in the range $0.0-0.024 \mathrm{mM}$ of fluoride $\left(0.0-1.0 \mathrm{mg} \cdot \mathrm{L}^{-1}\right)$. The molar absorptivity at $502 \mathrm{~nm}$ is $6.45 \times 10^{3} \mathrm{~L} \cdot \mathrm{mol}^{-1} \cdot \mathrm{cm}^{-1}$. Fluoride concentration higher than $1.0 \mathrm{mg} \cdot \mathrm{L}^{-1}$ can be measured after proper dilution. The sensitivity, detection limit, quantitation limit, and the percentage recovery of $0.75 \mathrm{mg} \cdot \mathrm{L}^{-1}$ fluoride for the method were found to be $0.357 \mu \mathrm{g} \cdot \mathrm{ml}^{-1}, 0.07 \mathrm{mg} \cdot \mathrm{L}^{-1}$, $0.2 \mathrm{mg} \cdot \mathrm{L}^{-1}$, and 101.1 respectively.
\end{abstract}

Keywords: Fluoride; Groundwater; Spectrophotometric Method; Aluminium Resorcin Blue Complex

\section{Introduction}

WHO (2006) [1] has considered fluoride as one of the very few chemicals that have been shown to cause significant effects in people. There is a narrow margin between the desired and harmful doses of fluoride [2]. Low concentration of fluoride in drinking water have been considered beneficial to prevent dental carries [3], but excessive exposure to fluoride can give rise to a number of adverse effects such as causing fluorosis $[1,4,5]$. WHO has set a limit value of $1.5 \mathrm{mg} \cdot \mathrm{L}^{-1}$ for fluoride in drinking water [6]. This necessitates an accurate, simple, rapid and cost effective analytical method is of high importance.

Spectrophotometric methods, which are widely used in the determination of fluoride, are based on the reaction of fluoride with coloured metal chelate complexes, producing either a mixed-ligand ternary complex or replacement of the ligand by fluoride to give a colourless metal-fluoride complex and the free ligand with a colour different of the metal-ligand complex [7].

Resorcin blue is used in literature as $\mathrm{pH}$ indicator for mineral acids, strong bases and alkaloids where the visual-transition interval is red at $\mathrm{pH} 4.4$ to blue at $\mathrm{pH} 6.4$ [8]. It is also used as a redox indicator in the titration of $\mathrm{Fe}(\mathrm{II}), \mathrm{As}(\mathrm{III}), \mathrm{Sb}(\mathrm{III}), \mathrm{U}(\mathrm{IV}), \mathrm{Mo}(\mathrm{V})$, hydroquinone, and oxalic acid with ammonium hexanitratocerate (IV) in

${ }^{*}$ Corresponding author.
$\mathrm{HClO}_{4}$ medium [9]. Resorcin blue is used in the determination of $\mathrm{Cr}(\mathrm{VI})$ [10], and for staining cellulose in plants [11].

The present study aimed to develop spectrophotometric method for determination of fluoride in drinking water using aluminium resorcin blue complex with fluoride ions.

\section{Experimental}

\subsection{Apparatus}

Beckman DU-7500 single beam spectrophotometer with $1.0 \mathrm{~cm}$ quartz cells was used for wavelength scanning and for spectral studies. Hitachi U-1500 UV/V is single beam spectrophotometer with $1.0 \mathrm{~cm}$ quartz cells was used for the absorbance measurements at fixed wavelength. Orion's Portable $210 \mathrm{~A} \mathrm{pH}$ Meter with Orion Triode electrode was employed for the $\mathrm{pH}$ measurements.

\subsection{Reagents}

Resorcin blue provided by Acros (339290050), and aluminum chloride hexahydrate (Purum p. a, 06232) provided by Fluka were used without any further purification. All the chemicals were of analytical reagent grade except where stated otherwise. Solutions were prepared using double distilled water. Resorcin blue ligand solution and the aluminum complex solution were prepared using ethanol from 
Merck (reagent 96\%, 159010). Standard fluoride stock solution was prepared by dissolving $0.1382 \mathrm{~g}$ of sodium fluoride provided by Merck (ACS reagent, 106449) in $250 \mathrm{ml}$ water. The stock solution was further diluted as needed.

\subsection{Preparing of the Metal Complexes Solutions}

Job's method of continuous variation was adopted for determination of the composition of the coloured complex $[12,13]$. Aluminium to ligand ratio was also studied by making comparison between the spectra of complexes of different metal to ligand ratios such as $1: 1,1: 2,1: 3,2: 1$, $3: 1,2: 3$, and $3: 2$. The blank was prepared by the same procedure using the solvent instead of the aluminum ion solution. Aluminum to ligand ratio was found to be 1:2.

The complex solutions for the spectrophotometric measurements were prepared by mixing aluminum 1:2 resorcin blue ratio of $5 \times 10^{-3} \mathrm{M}$ of aluminum and $5 \times 10^{-3} \mathrm{M}$ of resorcin blue in ethanol solution, which was then diluted to $\left(2 \times 10^{-4} \mathrm{M}\right)$ that is suitable for the spectrophotometric measurements. The stability of the complex in ethanol solution was examined for two weeks, and the complex is stable.

\subsection{Reaction of Fluoride with the Prepared Complexes Solutions}

Various amounts of fluoride were added in the range 0 $2 \mathrm{mg} \cdot \mathrm{L}^{-1}$ to $25 \mathrm{ml}$ volumetric flask containing aluminum 1:2 complex solution of resorcin blue in ethanol $\left(2 \times 10^{-4}\right.$ $\mathrm{M}, 24.5 \mathrm{ml}$ ). The solution was completed to volume by water. The absorbance was measured at the wavelength of the maximum difference between the absorption spectra of the complex and the ligand which was $624 \mathrm{~nm}$.

\subsection{Determination of Fluoride in Real Water Samples}

The method under investigation was tested using a real drinking water sample which had been collected and analysed by the Central Public Health Laboratory belonging to Ministry of Health and responsible for controlling water quality. The sample was collected in June 2011 from a groundwater well in Tubas District (Aqaba well). Fluoride was analysed colourimetrically using SPADNS as fluoride reagent and Hack-DR/2010 as spectrophotometer. Nitrate, sulfate, chloride, and other characteristic data of the sample are given in Table 1.

Table 1. Analytical data of Aqaba groundwater sample analysed by ministry of health laboratories.

\begin{tabular}{ccccccc}
\hline $\mathrm{pH}$ & $\begin{array}{c}\text { Conductivity } \\
\mu \mathrm{S} \cdot \mathrm{cm}^{-1}\end{array}$ & $\begin{array}{c}\text { Fluoride } \\
\mathrm{mg} \cdot \mathrm{L}^{-1}\end{array}$ & $\begin{array}{c}\text { Nitrate } \\
\mathrm{mg} \cdot \mathrm{L}^{-1}\end{array}$ & $\begin{array}{c}\mathrm{Chloride} \\
\mathrm{mg} \cdot \mathrm{L}^{-1}\end{array}$ & $\begin{array}{c}\text { Sulfate } \\
\mathrm{mg} \cdot \mathrm{L}^{-1}\end{array}$ & $\begin{array}{c}\mathrm{TDS} \\
\mathrm{mg} \cdot \mathrm{L}^{-1}\end{array}$ \\
\hline 7.17 & 826.00 & 0.68 & 0.33 & 90.33 & 87.00 & 413.00 \\
\hline
\end{tabular}

Fluoride was measured in the sample using aluminium resorcin blue 1:2 complexes and the obtained results were compared with that reported by the Central Public Health Laboratory using SPADNS method (Table 1 and Table 2). The method under investigation was tested using a real drinking water sample which had been collected and analysed by the Central Public Health Laboratory belonging to Ministry of Health and responsible for controlling water quality. The sample was collected in June 2011 from a groundwater well in Tubas District (Aqaba well). Fluoride was analysed colourimetrically using SPADNS as fluoride reagent and Hack-DR/2010 as spectrophotometer. Nitrate, sulfate, chloride, and other characteristic data of the sample are given in Table 1. Fluoride was measured in the sample using aluminium resorcin blue 1:2 complexes and the obtained results were compared with that reported by the Central Public Health Laboratory using SPADNS method.

\section{Results and Discussion:}

\subsection{Resorcin Blue and its Aluminium Complexes}

Resorcin blue is soluble in ethanol $\left(20 \mathrm{mg} \cdot \mathrm{mL}^{-1}\right)$, methanol, acetic acid and acetone, and slightly soluble in ether. Its solubility in water is $30 \mathrm{mg} \cdot \mathrm{mL}^{-1}$ [8]. Resorcin blue exhibits blue colour in ethanol solution and displays two bands in the visible region at 505 and $617 \mathrm{~nm}$ (Figure 1).

The molar absorptivity at these two wavelengths is $[5.98 \pm 0.12] \times 10^{3}$ and $[4.91 \pm 0.09] \times 10^{3} \mathrm{~L} \cdot \mathrm{mol}^{-1} \cdot \mathrm{cm}^{-1}$ respectively.

Table 2. Sensitivity, detection limit, quantification limit, and recovery of the method.

\begin{tabular}{cc}
\hline Parameters & Values at $624 \mathrm{~nm}$ \\
\hline Sensitivity $\left[\mu \mathrm{g} \cdot \mathrm{mL} L^{-1}\right]$ & $0.357 \pm 0.005$ \\
Detection limit $\left[\mathrm{mg} \cdot \mathrm{L}^{-1}\right]$ & 0.07 \\
Quantification limit $\left[\mathrm{mg} \cdot \mathrm{L}^{-1}\right]$ & 0.2 \\
Recovery of real water sample \% & $99.1 \pm 4.4$ \\
Recovery of $0.75 \mathrm{mg} \cdot \mathrm{L}^{-1} \%$ & $101.1 \pm 3.9$ \\
Recovery of $1.5 \mathrm{mg} \cdot \mathrm{L}^{-1} \%$ & $98.3 \pm 4.3$ \\
Recovery of $2.0 \mathrm{mg} \cdot \mathrm{L}^{-1} \%$ & $96.1 \pm 3.7$ \\
\hline
\end{tabular}

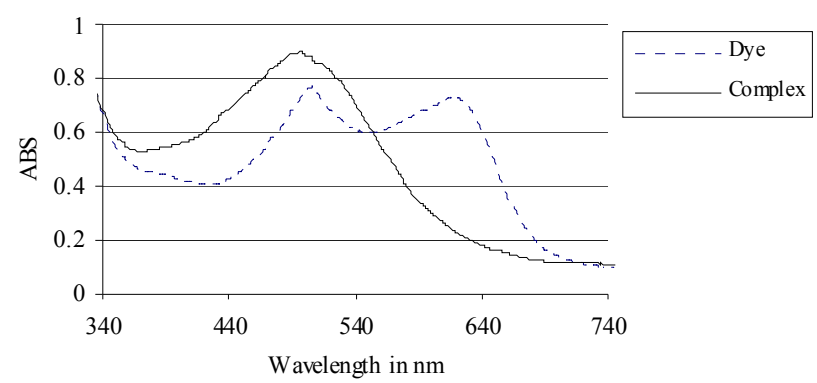

Figure 1. Electronic spectra of resorcin blue and its aluminium 1:2 complex in ethanol at $2 \times 10^{-4} \mathrm{M}$. 
The obtained results from applying of Job's method of continuous variation indicated that aluminium to resorcin blue complex ratio is $1: 2$. The ratio was also determined spectrophotometrically by comparing the spectra of aluminum resorcin blue complexes of different ratios with each others. A possible structure for the complex is given in Figure 2.

The complex exhibits brown colour in ethanol solution and has one band in the visible region at $502 \mathrm{~nm}$ (Figure 1) where the molar absorptivity is $[6.45 \pm 0.22] \times 10^{3}$ $\mathrm{L} \cdot \mathrm{mol}^{-1} \cdot \mathrm{cm}^{-1}$. Thus, there is hypsochromic shift (decrease in the wavelength) of about $115 \mathrm{~nm}$ after complexation with aluminum. This is resulting in a change in colour from that of the ligand, blue to the colour of the complex, brown.

Resorcin blue displays two bands in the visible region at 496 and $591 \mathrm{~nm}$ while its aluminium complex exhibits one band at $483 \mathrm{~nm}$ in water solutions. Therefore, using of water instead of ethanol as a solvent is resulting in a hypsochromic shift in the absorption spectra of the resorcin blue ligand and its aluminium complex of about 26 and $19 \mathrm{~nm}$, respectively. Thus, the solvent has a negative solvatochromism effect on the spectra of both of the ligand and it aluminium complex where increasing of the polarity of the solvent, as we move from ethanol to water, leads to a hypsochromic shift (a decrease in the wavelength) $[14,15]$. The difference in the absorption spectra between the complex and the ligand is bigger in ethanol than in water solution. This is due to the polarity of water and its ability to form hydrogen bonds in comparison with ethanol. This leads to destabilize the excited state which is expected be less polar than the ground state [15]. Therefore the effect of fluoride on the absorption spectra of the complex was examined in ethanol solution.

\subsection{Reaction of Fluoride with the Resorcin Blue Complex}

Fluoride reacts with the brown aluminium resorcin blue 1:2 complex to produce a colourless aluminium fluoride complex by replacement of the resorcin blue by fluoride and liberating of the free ligand. This is resulting in a change in the colour from that of the complex, brown to the colour of the free ligand according to the equation below. Aluminium reacts with fluoride to give compounds of the nature of $\left(\mathrm{AlF}_{6}^{-3}\right)$ or $\left(\mathrm{AlF}_{y}(\mathrm{OH})_{6-y}\right)^{-3}[16]$.

$$
\begin{aligned}
& \mathrm{Al}[\text { resorcin blue }]_{2}+6 \mathrm{~F}^{-1} \rightarrow \mathrm{AlF}_{6}^{-3}+2[\text { resorcin blue }] \\
& \text { Brown Colorless Blue }
\end{aligned}
$$

Fluoride interacts with complex under investigation to cause an increase in absorbance at $624 \mathrm{~nm}$ due to the releasing of the free ligand. The absorbance of the released free ligand is related linearly at $624 \mathrm{~nm}$ to the concentration of fluoride in the range 0.0 to $0.024 \mathrm{mM}(0.0$ to 1.0 $\mathrm{mg} \cdot \mathrm{L}^{-1}$ ) (Figure 3).

The squared correlation coefficient $\mathrm{R}^{2}$, is 0.993 , and the equation of the linear calibration curve is

$(y=0.3567 x+0.2773)$. The relationship of the reaction of fluoride with aluminum resorcin blue 1:2 complex was best described by a sixth-order polynomial function (Figure 4) where the squared correlation coefficient $R^{2}$, is 0.9982 . The reaction reaches equilibrium at fluoride concentration of $0.054 \mathrm{mM}\left(\approx 2.27 \mathrm{mg} \cdot \mathrm{L}^{-1}\right)$. The equilibrium constant $\left(K_{e q}\right)$ was calculated from the equilibrium equation below as $1.12 \times 10^{34}$. The large value for $K_{e q}$ indicates that the equilibrium lies far to the right.

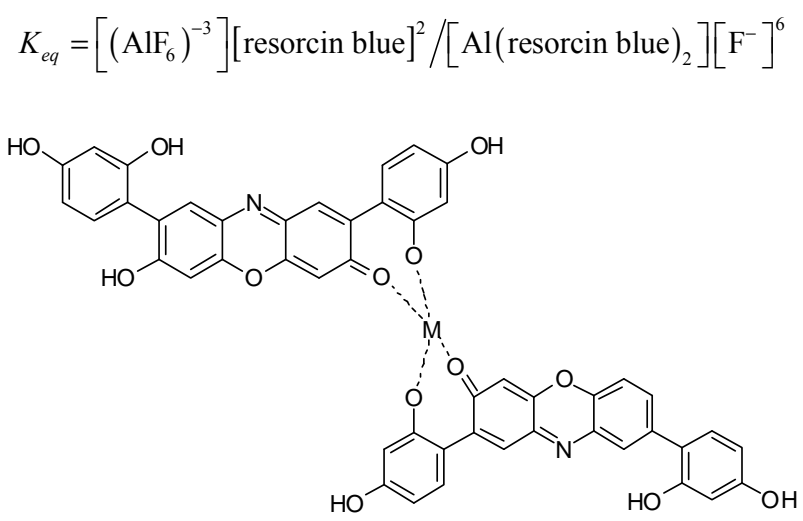

Figure 2. Possible structure for aluminium resorcin blue 1:2 complex.

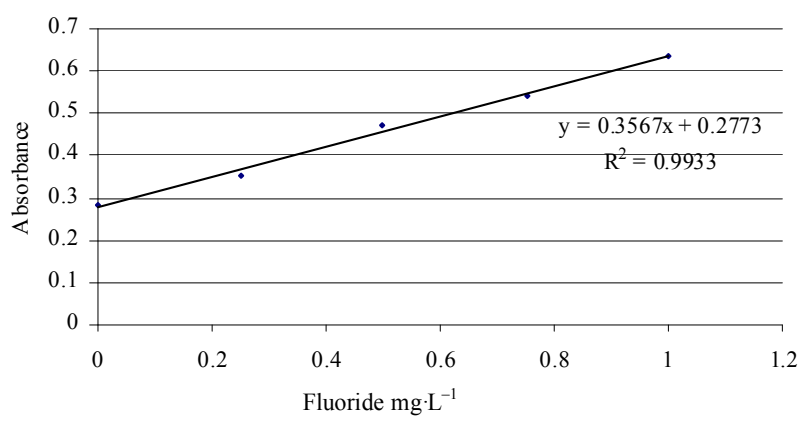

Figure 3. Calibration curve for determination of fluoride in the range $(0.0-1.0) \mathrm{mg} \cdot \mathrm{L}^{-1}$ at $624 \mathrm{~nm}$ by aluminum resorcin blue complex of $2.0 \times 10^{-4} \mathrm{M}$.

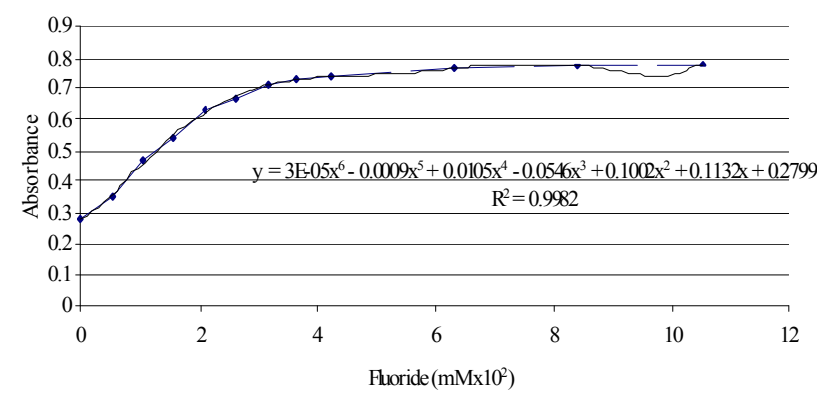

Figure 4. Absorbance of aluminum resorcin blue 1:2 complex of $2.0 \times 10^{-4} \mathrm{M}$ versus fluoride concentration in the range $0.0-0.119 \mathrm{mM}$ at $624 \mathrm{~nm}$. 
where: [resorcin blue] is measured using the molar absorptivity for resorcin blue, which was found to be $[5.67 \pm 0.07] \times 10^{3} \mathrm{~L} \cdot \mathrm{mol}^{-1} \cdot \mathrm{cm}^{-1}$ at $624 \mathrm{~nm}$, and the absorbance at the equilibrium;

$$
\begin{gathered}
{\left[\mathrm{Al}(\text { resorcin blue })_{2}\right] \text { is }} \\
{\left[\mathrm{Al}(\text { resorcin blue })_{2}\right]_{\text {initial }}-1 / 2[\text { resorcin blue }]} \\
{\left[\left(\mathrm{AlF}_{6}\right)^{-3}\right] \text { is } 1 / 2[\text { resorcin blue }]}
\end{gathered}
$$

and

$$
\left[\mathrm{F}^{-}\right] \text {is }\left[\mathrm{F}^{-}\right]_{\text {initial }}-\left[\left(\mathrm{AlF}_{6}\right)^{-3}\right] .
$$

Figures 3 and 4 show that aluminium resorcin blue complex is suitable for determination of fluoride in the range 0.0 to $1.0 \mathrm{mg} \cdot \mathrm{L}^{-1}$. The sensitivity, detection limit, limit of quantification, percentage recovery of fluoride in real water sample, and the percentage recovery of 0.75 , 1.5 , and $2.0 \mathrm{mg} \cdot \mathrm{L}^{-1}$ fluoride of the aluminium resorcin blue complex for the spectrophotometric determination of fluoride at $624 \mathrm{~nm}$ are given in Table 2.

The sensitivity was taken as the average of the slope of the calibration curve for five replicates. The detection limit and the limit of quantification were calculated as $(3.3 \sigma / \mathrm{S})$ and $(10 \sigma / \mathrm{S})$ respectively, where $\sigma$ is the standard deviation of response and $\mathrm{S}$ is the slope of the calibration curve.

The recovery was measured as the average of 10 replicate. The recover of high fluoride concentration such as 1.5 , and $2.0 \mathrm{mg} \cdot \mathrm{L}^{-1}$ fluoride was calculated by measuring the absorbance for the diluted solutions (1 to 3 ).

The interference studies were done by measuring the influence of the anions such as chloride, nitrate, and sulphate in such concentration commonly found in the natural water on the determination of $1.0 \mathrm{mg} \cdot \mathrm{L}^{-1}$ fluoride. Chloride and nitrate which were added in the range of $100-500$ and $5-100 \mathrm{mg} \cdot \mathrm{L}^{-1}$ respectively do not interfere with the determination of fluoride. Sulphate interferes with the most visual and photometric methods for determination of fluoride by its competition with fluoride to form a complex with the metal and therefore it results in higher concentrations $[17,18]$. In the present work, sulphate up to 100 $\mathrm{mg} \cdot \mathrm{L}^{-1}$ does not interfere with the determination of fluoride. However, at higher concentration, sulphate interferes with determination of fluoride by causing a positive error of about $25 \%$. This error can be overcome by precipitating sulphate in the cold by the addition of aqueous barium chloride solution and aqueous agar-agar solution, then to separate the precipitate by filtration [19].

The proposed spectrophotometric method can be applied without any previous preparations, such that were necessary to separate fluoride ions, to control fluoride in countries with low fluoride content water resources.

\section{Conclusions}

The relationship of the reaction of fluoride with alumin- ium-resorcin blue complex is related linearly at $624 \mathrm{~nm}$ to the concentration of fluoride in the range $0.0-1.0$ $\mathrm{mg} \cdot \mathrm{L}^{-1}$. However, at higher fluoride concentration, the relationship was best described by a sixth-order polynomial function. The reaction reaches equilibrium at fluoride concentration of $0.054 \mathrm{mM}$, and the equilibrium constant $\left(K_{e q}\right)$ was found to be $1.12 \times 10^{34}$.

Aluminium-resorcin blue complex was used successfully as new spectrophotometric reagent for determination of fluoride in water in the range 0.0 to $1.0 \mathrm{mg} \cdot \mathrm{L}^{-1}$. Due to its simplicity and high sensitivity, the method can be recommended as new spectrophotometric reagent for determination of fluoride in drinking water at low concentration. However, determination of fluoride at higher concentration is possible by diluting of the water sample to fit the requirements of the proposed method.

\section{Acknowledgements}

The authors thank Professor Walter Kosmus from the Analytical Chemistry Institute in the University of Graz-Austria for his advices, suggestions, ideas, comments, helpful discussions, and for his supervision through the $\mathrm{Ph}$. D research. The Director (Mr. Ibrahim Salem) and the staff of the Central Public Health Laboratory-Ministry of Heath are highly acknowledged for their cooperation and for sharing their data.

\section{REFERENCES}

[1] WHO, "Fluoride in Drinking-Water," IWA Publishing, London, 2006, pp. 1-3, 83-95.

[2] W. Czarnowski, K. Wrzesniowska and J. Krechniak, "Fluoride in Drinking Water and Human Urine in Northern and Central Poland," Science of the Total Environment, Vol. 191, No. 1-2, 1996, pp. 177-184. doi:10.1016/0048-9697(96)05259-X

[3] S. M. Maliyekkal, S. Shukla, L. Philip and I. M. Nambie, "Enhanced Fluoride Removal from Drinking Water by Magnesia-Amended Activated Alumina Granules," Chemical Engineering Journal, Vol. 140, No. 1-3, 2008, pp. 183-192. doi:10.1016/j.cej.2007.09.049

[4] Y.-N. Wang, K. Q. Xiao, J. L. Liu, G. Dallner and Z. Z. Guan, "Effect of Long Time Fluoride Exposure on Lipid Composition in Rat Liver," Toxicology, Vol. 146, No. 2-5, 2000, pp. 161-169. doi:10.1016/S0300-483X(00)00167-0

[5] M. A. Armienta and N. Segovia, "Arsenic in Fluoride in Groundwater of Maxico," Environmental Geochemistry and Health, Vol. 30, No. 4, 2008, pp. 345-353. doi:10.1007/s10653-008-9167-8

[6] WHO, "Guidelines for Drinking-Water Quality. Recommendation," 2nd Edition, Vol. 1, World Health Organization, Geneva, 2004, pp. 375-377.

[7] H. Einaga and I. Iwasaki, "Spectrophotometric Study of the Reaction of Zirconium with Chrome Azurol S and Fluoride," Talanta, Vol. 28, No. 12, 1981, pp. 889-900. 


\section{doi:10.1016/0039-9140(81)80224-X}

[8] F. J. Green, "The Sigma-Aldrich Handbook of Stains, Dyes and Indicators," Aldrich Chemical Company, Milwaukee, 1990, p. 624.

[9] N. V. Rao and K. R. Murty, Journal of the Indian Chemical Society, Vol. 56, 1979, pp. 641-642.

[10] H.-Z. Wu, Z.-R. Wu, J. Lin and Z.-S. Zheng, "Catalytic Spectrophotometric Determination of Trace Chromium (VI) with Sensitization Effect of Surfactant," Fenxi Shiyanshi, Vol. 18, 1999, pp. 26-29.

[11] M. Ulrychova, E. Petru and Z. Pazourkova, "Permanent Staining of Callose in Plant Material by Ponceau," Stain Technol, Vol. 51, No. 5, 1976, pp. 272-275.

[12] L. Werner and D. F. Boltz, "Theory of Contineous Variations Plots and a New Method for Spectrophotometric Determination of Extraction and Formation Constant," Analytical Chemistry, Vol. 43, No. 10, 1971, pp. 12651272. doi:10.1021/ac60304a006

[13] L. Werner and D. F. Boltz, "Spectrophotometric Determination of Extraction Constants of Certain Metal 1-Pyrrolidinecarbodithioates," Analytical Chemistry, Vol. 43,
No. 10, 1971, pp. 1273-1277.

[14] P. F. Gordon and P. Gregory, "Organic Chemistry in Colour,” Springer-Verlag, Berlin, 1983, p. 303.

[15] H. Zollinger, "Colour Chemistry: Syntheses, Properties, and Applications of Organic Dyes and Pigments," Verlag Helvetica Chimica Acta, Zuerich, 2003, p. 42.

[16] B. J. Macnulty, C. J. Hunter and D. G. Barrett, "The Determination of Microgram Quantities of Fluoride: The Use of Aluminium-Eriochromecyanin Complex," Analytica Chimica Acta, Vol. 14, pp. 1956, 368-380.

[17] M. J. Price and O. J. Walker, "Determination of Fluoride in Water," Analytical Chemistry, Vol. 24, No. 10, 1952, pp. 1593-1595. doi:10.1021/ac60070a018

[18] J. A. Ruzicka, H. Jakschova and L. Marklas, "Determination of Fluorine in Bones and Teeth with Xylenol Orange," Talanta, Vol. 13, No. 9, 1966, pp. 1341-1344. doi:10.1016/0039-9140(66)80224-2

[19] E. J. Dixon, "Determination of Micro Amounts of Fluoride with Zirconium and Solochrome Cyanine R.," Analyst, Vol. 95, No. 1128, 1970, pp. 272-277. 